\title{
COMUNICAÇÃO VISUAL NO AMBIENTE DIGITAL: DISPOSITIVOS E PERFORMANCE TIPOGRÁFICA NAS CAPAS DA REVISTA ELLE
}

\author{
VISUAL COMMUNICATION IN DIGITAL ENVIROMENT: DEVICES AND \\ TYPOGRAPHIC PERFORMANCE ON THE COVERS OF ELLE MAGAZINE \\ COMUNICACIÓN VISUAL EN AMBIENTE DIGITAL: DISPOSITIVOS Y \\ DESEMPEÑO TIPOGRÁFICO EN LAS PORTADAS DE LA REVISTA ELLE
}

Audrey Marques Duarte

Marli dos Santos

Resumo: a variedade de dispositivos digitais fixos e móveis impacta na comunicação visual presente em veículos, como na tipografia das capas de revistas em ambiente virtual. A qualidade também está ligada à forma de apresentação dos conteúdos, cujas características essenciais são a legibilidade e a usabilidade. Este estudo engloba a interação entre comunicação, tipografia digital e revistas. O objetivo é explorar o ambiente da tipografia digital e sugerir critérios para controle de qualidade da presença tipográfica nas plataformas digitais. A pesquisa é qualitativa, de cunho descritivo, e analisa as capas de Elle Brasil em ambientes digitais, por meio de categorias de legibilidade e usabilidade. Com base nas análises, verificamos que a qualidade da presença tipográfica em ambiente digital deve abranger a identidade do veículo de comunicação e as características da plataforma, mantendo a legibilidade. A presença da usabilidade nos equipamentos corrige eventuais desconfortos e torna a leitura satisfatória.

Palavras-chave: Comunicação Visual. Tipografia Digital. Revista Elle Brasil.

Abstract: the variety of fixed and mobile digital devices impacts the visual communication in media outlets, such as the typography of magazine covers in a virtual environment. The quality is also related to how the contents are presented, which key features are the readability and usability. This study encompasses the interaction between communication, digital typography and magazines. The purpose is to explore 
the digital typography environment and suggest criteria to control the quality of the typographic presence in digital platforms. The research is qualitative, descriptive, and analyzes the covers of Elle Brasil in digital environments through readability and usability categories. Based on the analyses, we have seen that the quality of the typography presence in digital environment must encompass the identity of the media outlet and the characteristics of the platform, maintaining the readability. The presence of usability in devices corrects eventual discomforts and makes reading a pleasant experience.

Keywords: Visual Communication. Digital Typography. Elle Brasil Magazine.

Resumen: la variedad de dispositivos digitales fijos y móviles impacta la comunicación visual presente en vehículos, como la tipografía de las portadas de revistas en entorno virtual. La calidad también está relacionada a la forma de presentación de contenidos, cuyas características esenciales son la legibilidad y la usabilidad. Este estudio incluye la interacción entre comunicación, tipografía digital y revistas. El objetivo es explorar el entorno de la tipografía digital y sugerir criterios para control de calidad de la presencia tipográfica en plataformas digitales. La investigación es cualitativa, descriptiva y analiza las portadas de Elle Brasil en entornos digitales, por medio de categorías de legibilidad y usabilidad. Con base en los análisis, hemos verificado que la calidad de la presencia tipográfica en entorno digital debe cubrir la identidad del vehículo de comunicación y las características de la plataforma, manteniendo la legibilidad. La presencia de la usabilidad en los equipos corrige eventuales incómodos y hace la lectura satisfactoria.

Palabras claves: Comunicación Visual. Tipografía Digital. Revista Elle Brasil.

\section{Introdução}

Paste-upscíceros paicas fotolitos artes-finais nanquim colagens... Esse repertório tão usado entre diagramadores, jornalistas e designers na tipografia impressa, torna-se outro em tempos de tecnologias digitais, e os domínios profissionais também. Seja pela dinâmica mais veloz, seja pelas telas iluminadas ou pela multimidialidade - texto, imagens em movimento (vídeos) e áudio (trilhas sonoras, efeitos etc.), a comunicação das mensagens visuais passou a ser altamente utilizada e está presente em todos os dispositivos - sejam eles fixos (desktop) ou móveis (smartphones, tablets e notebooks), com o público, ao mesmo tempo, sendo receptor e emissor de mensagens visuais.

Manter e/ou ampliar a audiência é uma meta das empresas jornalísticas, e, para isso, o controle de qualidade da produção visual por meio de critérios e instrumentos que auxiliem aqueles que participam do processo criativo e 
operacional/produtivo, como editores e designers em ambientes digitais, inclui a tiporafia como um elemento essencial.

Este artigo trata do uso dos tipos gráficos em meios digitais (tipografia digital) e sua aplicação nas capas da Revista Elle. A escolha do meio revista ocorreu por este ser um produto que necessita de contemplação do leitor, ou seja, não se trata apenas de uma relação instrumental no sentido de conhecer as principais manchetes do dia. Já a opção pela Elle Brasil se justifica por sua presença em diversas plataformas fixas e móveis digitais; pela longevidade dessa publicação, com mais de 70 anos; pela abrangência mundial; e por ser representada no Brasil por um dos maiores grupos editoriais do país, o Grupo Abril. As capas foram o foco de análise por sua importância como porta de entrada para a publicação, seja no impresso ou no ambiente digital. É também onde a identidade visual do veículo se expressa, com a forte presença de sua logomarca e as estratégicas chamadas de capa.

A pergunta-problema da pesquisa é: como se apresenta a performance da tipografia na capa de publicação em versão digital, para atender satisfatoriamente os requisitos do controle da produção dos elementos visuais que compõem as capas de revista nesse ambiente? O objetivo geral foi investigar os elementos tipográficos presentes na versão impressa da capa da revista Elle Brasil em ambiente digital, por meio dos dispositivos desktop, notebook, tablet e smartphone. Ressalta-se que o estudo não se aprofunda sobre o aspecto morfológico da tipografia, e sim no que ela, associada a outros aspectos, pode colaborar na leiturabilidade e usabilidade em dispositivos digitais.

Dessa forma, foram selecionadas dez capas da revista Elle Brasil, de abril de 2016 a fevereiro de 2017 (a edição de maio/2016 não foi disponibilizada pelaEditora Abril/GoRead ), constituindo uma amostra não probabilística, do tipo intencional. As capas foram observadas em suas versões em desktop, notebooks, tablets e smartphones. Como dito anteriormente, a legibilidade e leiturabilidade são essenciais para que haja qualidade no processo comunicacional, por isso a presença da tipografia nesses suportes depende das condições do próprio suporte.

A tipografia aplicada às capas de Elle foi analisada por meio da criação de uma ficha de protocolo, com duas grandes categorias: legibilidade (que diz respeito diretamente à tipografia) e usabilidade (que diz respeito à plataforma). Também foi realizada entrevista semiestruturada com especialista, na qual pudemos explorar: 1) o formato do meio revista no ambiente digital; 2) a especialização no jornalismo; 3) a comunicação visual e a tipografia na transição entre impresso e digital; 4) a tecnologia presente nos dispositivos móveis. Em tópico posterior, detalharemos o desenho da pesquisa, bem como os aspectos considerados nessas duas categorias. 
No levantamento bibliográfico, foram considerados os conceitos de comunicação visual de Dondis (1991), Munari (1997), Canevacci (2001), Zapaterra (2014) e Gruzinski (2015). Quanto à revista e capa de revista, temos Ali (2009), Barbosa $(2013,2017)$ e Longhi (2009). A tipografia é tratada sob perspectivas de Bringhurst (2001), Marques (2008), Carramilo (2008), Spiekermann (2011) e Lupton (2013). Sobre a tipografa digital abordamos Schakel (1991), Farias (2003), Radfahrer (2008), Lupton (2015) e Duarte (2017) e, por fim, a legibilidade e a usabilidade têm as contribuições de Nielsen (1993), Fadel e Licheski (2013) e Rogers (2013).

\section{Comunicação visual e tipografia}

Entendemos a comunicação visual, tal qual a definição de Munari (1997, p. 18), como "imagens que nos rodeiam". A concepção da comunicação visual como imagens diversas, aquelas que fazem parte do mundo e aquelas que são nossas, no passado e no presente, amplia o conceito de comunicação visual. Essas imagens não estão restritas ao pictórico, mas ao conjunto de signos e símbolos que povoam o nosso cotidiano.

Mas a comunicação visual não é linear, e sim objeto de misturas ocorridas ao longo do tempo. Na visão de Canevacci (2001), a escritura visual se insurge para romper com a linearidade, recusando "o nexo da continuidade, tranquilizador e organizador das sequências (sic) discursivas". Esta detecção não nos afasta, mas nos aproxima pela experiência e observância dos variados fenômenos que ocorrem na comunicação visual e que incitam a curiosidade científica sobre as insurgências, tendo em vista a evolução tecnológica. A comunicação visual é fundamental não somente para construir a mensagem visual como também para compreendê-la. É como se estivéssemos lendo um texto para entender as informações que a imagem como um todo nos traz.

A comunicação visual não se apresenta linear, mas como artifício composto por misturas contínuas, trocas e interfaces de visões, associações e abstrações. Tudo se vira continuamente para seu oposto. Como em nossa ampulheta, onde o tempo de queda dos grãos de areia é sempre o mesmo, porém sua ordem é caótica (CANEVACCI, 2001, p. 90).

A continuidade e descontinuidade na comunicação visual podem ser pensadas a partir da presença de certos elementos que a constituem. Dondis (1991, p. 30-40) aponta esses elementos: ponto ("unidade de comunicação visual mais simples e irredutivelmente mínima"); linha (pontos que se unem em uma cadeia, 
dando sensação de direção); forma (linhas que descrevem três formas básicas: quadrado, círculo e triângulo equilátero); direção ("todas as formas básicas expressam três direções visuais básicas e significativas: o quadrado, a horizontal e a vertical; o triângulo, a diagonal, o círculo, a curva"); tom ("intensidade da obscuridade ou claridade de qualquer coisa vista"); cor; textura (elemento que simula materiais, pode ser reconhecida pelo tato ou visão, ou a os dois), escala (relação de tamanho entre elementos, que reproduz o real); dimensão (simulação de um objeto da realidade por meio principalmente da perspectiva, é mais implícito que explícito); e movimento ("se encontra mais frequentemente implícito do que explícito no modo visual. Contudo, o movimento talvez seja uma das forças visuais mais dominantes da experiência humana"). A tipografia relaciona-se com todos esses elementos, sem que haja conflito, coexistindo e inter-relacionando-se com os elementos da comunicação visual, criando sintaxes criativas, previsíveis, redundantes ou entrópicas.

Já Guimarães (2013, p. 238), quando se refere à comunicação visual no ambiente jornalístico, a denomina como "material jornalístico verbal com imagem", citando a "tipografia, fotografia, ilustrações, videografias etc."), em uma "organização espaço-temporal ditada pelo design gráfico em um conjunto significante espacialmente delimitado pelo suporte de determinada mídia". Assim, a evolução da comunicação visual no jornalismo acompanha a evolução tecnológica, sem perder o lastro com a "tradição da escrita" e da imagem (p. 239).

Nesse sentido, a tipografia digital colabora com a evolução da comunicação visual, como outros elementos, "para compor visualmente os caracteres (letras, numerais, sinais e ornamentos) que levam à construção da mensagem escrita" (DUARTE, 2017, p. 62). Os conjuntos de tipos são desenvolvidos para um entendimento universal, buscando-se o compartilhamento. Por isso é um elemento que ajuda na recepção das mensagens facilitando a leitura, trazendo conforto visual e facilidade de entendimento, assim como as imagens podem fazê-lo, o que impacta diretamente na aproximação e permanência do leitor no momento em que interage com o conteúdo editorial, conforme comentam Caldwell e Zapaterra (2014, p. 10 ): " O design de material editorial cumpre diferentes funções, tais como dar expressão e personalidade ao conteúdo, atrair e manter os leitores e estruturar o material de forma clara".

Nem sempre a tipografia domina o design gráfico, porém, ganha destaque quando se pensa no tamanho, no movimento, na cor, na localização do texto dentro da composição da página. A tipografia sempre vai colaborar para equilibrar os elementos da página visualmente, cumprindo um papel importante na 
comunicação visual. Em outros momentos ela é dominante e passa a ser central na composição, adequando a fonte tipográfica ao assunto que está sendo tratado, o relacionamento da fonte com o conteúdo a ser impresso, conforme nos traz Spiekermann (2011):

Na verdade, o aspecto e a personalidade de um jornal são obtidos pela tipografia usada e pelo modo como está disposta na página. Reconhecemos facilmente nosso jornal favorito na banca, mesmo se olhamos apenas um canto da página [...] (SPIEKERMANN, 2011, p. 13).

A diversidade de tipos ou de famílias de fontes também colabora para o sentido da mensagem, sendo que os elementos utilizados em sua composição abrangem letras, números, sinais e ornamentos. Porém, as letras são elementos centrais na tipografia, porque se responsabilizam pelo trânsito da mensagem. De acordo com Lupton (2013, p. 9), originalmente há uma relação fundamental entre os gestos do corpo e as palavras, pois os primeiros tipos imitavam as formas da caligrafia, só que com uma característica de manufatura infinita. De acordo com a autora, há uma tensão permanente entre o humano e a máquina, o orgânico e o geométrico e o corpo e o sistema abstrato.

Deve-se lembrar também que as escolhas feitas dentre os elementos gráficos para construir a mensagem devem buscar características próprias de acordo com o meio em questão e tudo o que se relaciona com o mesmo (comportamento do leitor para leitura de uma revista impressa ou visualização da mesma revista em um tablet, por exemplo). Esta vertente do design gráfico - a qual trata de livros, revistas, jornais etc. - denominada design editorial, tem no conteúdo seu principal atrativo e isto ocorre tanto para aquele que o produz, quanto para quem o recebe e dissemina, conforme comenta Gruzynski (2015) em seu artigo Design Editorial e Publicação Multiplataforma:

[...] o trânsito e a permeabilidade entre elementos de uma cultura letrada e uma emergente cultura digital, abre espaço para que o design editorial atue com o propósito de desenvolver produtos e processos mediante os possíveis significados que vêm sendo acrescentados, subtraídos e transformados em relação ao conjunto das formas significativas (GRUZYNSKI, 2015, p. 585).

Portanto, a variação dos tipos é muito ampla, tão ampla quanto a capacidade humana de criar, e possui variadas estruturas, de acordo com a família (grupo 
de tipos com características semelhantes) e que definem a estrutura exclusiva, integral ou parcial, de cada família de fonte quando em comparação com outra.

A estrutura das fontes é composta por detalhes, que ajudam a identificar as características de um tipo, constituindo um elenco de referências para a criação de novas fontes, inclusive no ambiente digital. Há muito o que dizer sobre a tipografia, mas o que nos interessou aqui foi destacar a sua importância na comunicação visual e no jornalismo, além de suas características e diversidade para a composição de uma mensagem.

\section{Tipografia digital: legibilidade e usabilidade}

No ambiente digital, há uma mudança na relação com os aspectos visuais das mensagens escritas. Comecemos pela palavra fonte, que passou a fazer parte do vocabulário comum dos usuários. Isso porque alguns recursos propiciados pelos dispositivos digitais permitem ações que anteriormente não eram possíveis, como a ampliação da fonte pela tactilidade na tela do smartphone, além da manipulação feita pelo próprio receptor da mensagem, que pode acrescentar elementos à composição. Nesse novo cenário, a tipografia ganhou características ainda mais experimentais e criativas, pois a facilidade de manipular por meio de softwares gráficos e o potencial dos hardwares oferecem inúmeras opções com rapidez, conforme Marques (2008, p. 2), “[...] os processos ópticos da fotocomposição passaram a respeitar a informática: o ponto Didot, o Cícero e a Paica foram substituídos pelo pixel, pelo bit e pelo byte".

Radfahrer (2008, p. 105) relembra que os processos mecânicos ainda faziam parte do cotidiano nos anos 1980. E que "A Desktop Publishing, viabilizada pelos produtos das empresas Apple - Xerox - Adobe - Aldus - Linotype, só se tornou realidade fora dos Estados Unidos no início dos anos 9o" (2008, p. 105). Duarte (2017) menciona que as transformações tecnológicas foram diversas para atender as demandas e os desejos de diferentes profissionais e públicos:

Dentre eles, estão TVs de alta definição; mídias de armazenamento (pendrive, cartões de memória); processadores e chips gráficos; GPS Global Positioning System; Tocadores portáteis de CD, equipamentos reprodutores e produtores de vídeos, músicas e fotografias (MP3, iPods); telefones inteligentes que integram computadores (smartphones); computadores portáteis (notebooks); transmissão por redes sem fio; banda larga para transmissão de dados (permite navegação de alta velocidade); e motores de busca (como o Google) (Hamann, 
2010). Alguns desses aparelhos utilizam as interfaces gráficas para a interatividade com seus públicos, como os smartphones e tablets, que por meio de determinadas inovações estimulam o desenvolvimento da tipografia permitido (DUARTE, 2017, p. 145).

A tipografia digital trouxe facilidade nos processos de criação, repercutindo também em compartilhamento entre usuários. Nesse sentido, a estrutura dos tipos e a composição devem ser pensadas para a legibilidade, para abranger a facilidade e o conforto pela leitura (FARIAS, 2003). Outro termo utilizado no universo tipográfico é leiturabilidade, sendo que alguns diferenciam legibilidade de leiturabilidade e outros, como a autora já referida, consideram que se complementam:

[...] leiturabilidade, ao nível dos caracteres, pode ser definida como a capacidade de uma determinada fonte de dar forma ao texto sem requerer um esforço adicional do leitor. Se considerarmos, porém, que o cansaço de um leitor frente a um texto pode ser motivado por muitos outros fatores que não o desenho da fonte com a qual ele foi atualizado, compreenderemos porque o termo leiturabilidade é evitado por outros autores [...] As pesquisas sobre rapidez e conforto [...], contudo, não chegaram a qualquer constatação definitiva, a não ser a conclusão comum de que certos aspectos do processo de leitura dificilmente poderiam ser medidos de forma objetiva (FARIAS, 2013, p. 104-105).

Na pesquisa apresentada neste artigo adotamos o termo legibilidade - que absorve a leiturabilidade, considerando que pode ocorrer influência no caso da tipografia digital, dependendo do dispositivo. Esses aspectos estão ligados à resolução das telas, por exemplo. A legibilidade deve-se ao movimento da fonte, tamanhos/corpos das fontes, fontes com e sem serifa, uso de caixas alta e baixa, uso de itálico, uso de bold, alinhamento, cor, figura e fundo e textura. A relação harmoniosa entre esses elementos traz conforto, facilidade e rapidez na leitura.

Mas há ainda outro aspecto importante na tipografia digital: a usabilidade, a qual ocorre quando a aprendizagem é facilitada; quando propicia boa performance na realização de tarefas, ou seja, é eficiente; é fácil de relembrar os procedimentos de uso; e quando é agradável ao ser usada e há baixo nível de erro (NIELSEN, 1993, p. 45).

Finalmente, a acessibilidade é importante para a tipografia digital porque engloba a capacidade funcional. De acordo com Schakel (1991, p. 22), as tarefas em um determinado contexto, não devem exigir esforço, treinamento ou su- 
porte. Assim, uma revista no ambiente digital deve potencialmente ser acessível ao seu leitor.

\section{Elle digital}

A revista Elle impressa foi lançada em 21 de novembro de 1945, na França, no pós-guerra. Em um país e continente que precisavam se reconstruir, ela especializou-se em moda e em estilo de vida, tendo à frente sua criadora, de naturalidade russa e criada em Paris, Hélène Lazareff (Elle International Network, 2017). No primeiro número não há chamadas de capa, porém, percebe-se que a imagem já é anunciada com forte apelo ao perfil editorial da revista, conforme vemos a seguir (Figura 1).

Figura 1 - A primeira capa de Elle, 1945

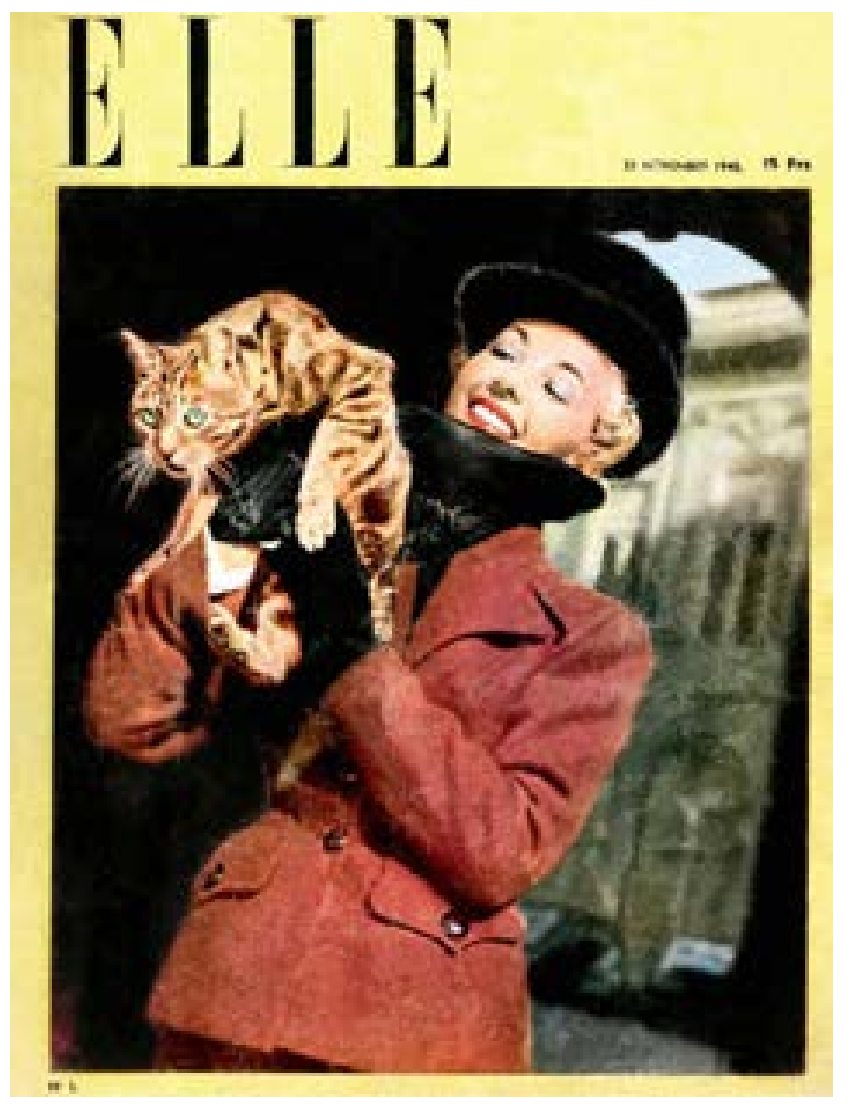

Fonte: Extraído do artigo Elle...(2014).

Até a década de 1980 era uma publicação apenas francesa, mas é nesse período que se expande internacionalmente, tornando-se uma marca global. No 
Brasil, chega em 1989. A partir de 2002, as modelos e celebridades das capas de lançamento nos países passam a mostrar quase o corpo inteiro (antes, somente o rosto era utilizado, salvo uma ou outra exceção). Já a tipografia utilizada no logotipo perpetua a força da representação gráfica da marca em todos os suportes, elemento de extrema relevância na ligação com seu público.

A ampliação da revista Elle se deu não só do ponto de vista geográfico, mas também no ambiente digital, em diversas plataformas, como site e redes sociais (GABRIEL, 2010). A revista impressa faz pontes com as outras plataformas onde o conteúdo editorial e a identidade visual estão expostos, colocando em prática a convergência tecnológica (BARBOSA, 2013), em que os conteúdos estão presentes em vários suportes. Em entrevista para esta pesquisa, Suzana Barbosa (2017) destaca que:

\begin{abstract}
A revista tem hoje a preocupação de também poder oferecer o seu conteúdo, produto, e também estar presente em outras plataformas porque a revista Elle, falando especificamente, assim como outras revistas semanais e mensais de moda, com as suas especificidades temáticas e distintas, estão e têm buscado fazer a adequação a uma outra realidade - e isto já faz alguns anos - o digital. [...] O que é importante? Quando a gente fala de convergência jornalística a ideia é justamente que uma empresa jornalística, uma organização jornalística, tem que pensar bem no seu produto, o seu produto estar circulando em várias plataformas. Não dá para ele ficar restrito apenas à forma impressa porque ele tem um público específico que gosta do impresso e outro que não vai consumir o impresso ou vai, principalmente, para o tablet (Informação verbal).
\end{abstract}

Algumas ações da Elle Brasil direcionam o leitor a interagir em plataformas e dispositivos diferentes, ampliando a experiência informativa. Os leitores são conduzidos aos dois ambientes ao mesmo tempo, em vez de ficar em apenas um deles. Estratégia que exige recursos, como investimentos em tecnologia da informação (TI), servidores capacitados para atender à demanda tecnológica, entre outros elementos para manter a qualidade da infraestrutura, mas que mantém a relação entre o impresso e o digital.

As novas estratégias alargam as possibilidades de perenidade de um conceito de revista, até então apenas relacionado ao impresso. Duarte (2017, p. 233) analisa que "Convergir as plataformas obtendo um efeito de complementaridade e troca de conteúdos e experiências de leitura com o meio agrega valor à marca Elle”. Além do que, como diz Longhi (2009, p. 188), explora-se "as possibilidades 
de convergência de linguagens própria do meio digital" e também se propõe "fusões conceituais que resultam em formas inovadoras de informação". A revista Elle se manteve em sintonia com as tendências da comunicação em revista, direcionando a sua atenção não somente para a forma de disponibilização, como também o conteúdo noticioso e publicitário existente nela.

\section{A atração das capas}

O termo capa nos remete ao impresso. Nos produtos nativos digitais se atribui à home esse impacto, como no caso de sites e portais. Em se tratando da versão digital da revista Elle, verificamos que se mantém, na capa - até por estratégia mercadológica - versão semelhante à impressa.

A capa é responsável por atrair a atenção: "é a página mais importante" da publicação, diz Ali (2009, p. 68), portanto, precisa fisgar o leitor rapidamente. No mundo analógico, "Uma revista tem 5 segundos para atrair a atenção do leitor na banca. Nessa fração de tempo, a capa tem de transmitir a identidade e o conteúdo da publicação, deter o leitor, levá-lo a pegar o exemplar, abri-lo e comprá-lo [...]", ressalta a autora (2009, p. 67).

Barbosa (2017), em entrevista para esta pesquisa, confirma a ideia da capa como atrativo, e menciona que nela "há vários paratextos". Dessa forma, continua a pesquisadora, "Pode-se classificar de possibilidades de entrada, de leitura, pois eu sei que há; está em destaque ali! Quando eu entro, eu já quero ir direto naquela matéria que me interessa [...]" (Informação verbal).

No ambiente digital o hábito de consumo de revista muda, pois ainda é publicação mais lida no formato impresso. De acordo com a Secretaria de Comunicação Social da Presidência da República (2016, p. 23) na Pesquisa Brasileira de Mídia $2016,67 \%$ dos leitores de revista preferem a forma impressa, sendo que $26 \%$ costumam acessar versões digitais. Talvez seja por isso que a revista Elle, na sua versão digital, reproduza a capa da edição impressa. A ideia de reforço ao formato impresso continua fortemente presente no acesso pelos dispositivos no ambiente virtual, disponível em desktop, notebook, tablet ou smartphone.

$\mathrm{Na}$ sua identidade visual Elle comunica que aquele conteúdo tem origem naquela revista impressa, dando autenticidade e valor ao digital. Conforme Barbosa (2017), a preocupação com a identidade visual e gráfica é primordial, porque se torna referência em qualquer plataforma com a qual o leitor entra em contato. Por isso, a Elle, estrategicamente, oferece em plataformas diferentes a mesma capa, uma forma para que o público a reencontre a cada nova edição, cada post 
feito em redes sociais, cada análise de tendências de moda que venha a oferecer cotidianamente durante uma nova estação. As condições tecnológicas que levam a essas ações são condições convenientes e pertinentes à manutenção da identidade da revista, com critérios de legibilidade e usabilidade.

O logotipo de Elle é baseado na fonte Didot, com as devidas alterações e ajustes que as fontes permitem aos designers gráficos (no logotipo de Elle a fonte apresenta-se de forma condensada, diferente de seu original). Mas há uma mescla de fontes no projeto gráfico da revista Elle Brasil, tendo como base na capa as fontes tipográficas Didot e Garamond (mais tradicionais e clássicas) e Futura (mais moderna), além da utilização das famílias dessas fontes - começando pelo logotipo da revista (Didot) até as chamadas de capa (mescla de Didot, Garamond, Futura etc.). As decorrências são, principalmente, o trabalho com as variações entre caixa-alta e baixa, itálico e normal e também entre bold e normal. A relação das fontes com os outros elementos (cores, movimentos e imagens, por exemplo) é que garantem a legibilidade e características exclusivas à identidade visual da revista, conforme podemos ver na figura 2 . 
Figura 2 - A presença das fontes tipográficas na capa da Elle Brasil, edição $\mathrm{n}^{\circ}$ 344, janeiro de 2017

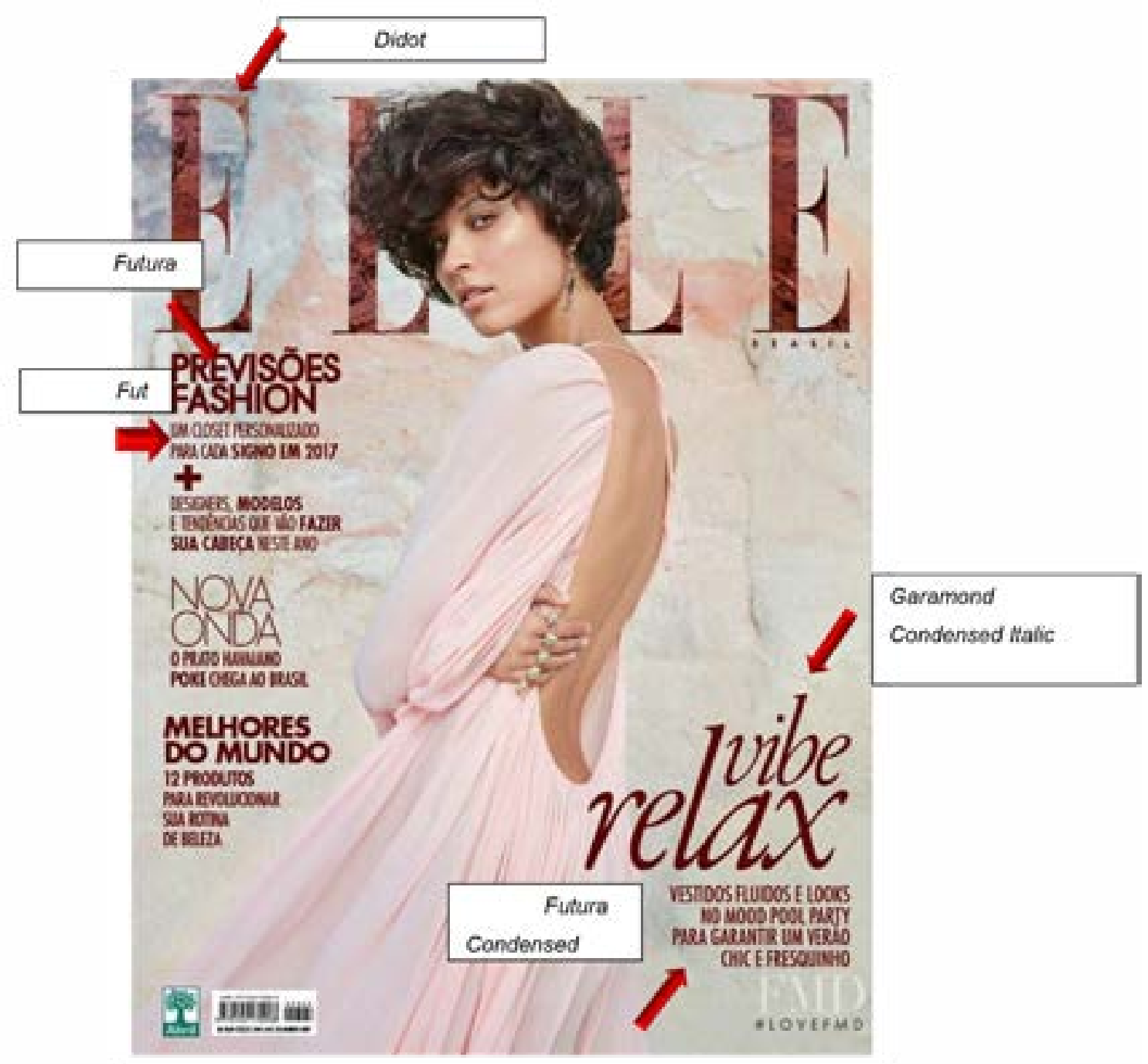

Fonte: ELLE BRASIL (2017a).

Categorias de análise da tipografia digital em Elle

Para o estudo aqui proposto, as categorias de análise foram estabelecidas a partir da revisão de literatura, que incluiu os elementos da comunicação visual e da tipografia digital. A seguir, explanamos as categorias. 


\section{Legibilidade/Leiturabilidade}

A legibilidade, como já dissemos, é um dos fundamentos da tipografia digital. Ela organiza, estrutura, apresenta (entre outros) o texto, promovendo facilidade e conforto pela leitura. Esta categoria está dividida em dez subcategorias de análise, que englobam os elementos da comunicação visual citados por Dondis (1991), os quais estão relacionados com a estrutura das fontes tipográficas. Vale observar que, dentre as subcategorias que apresentamos a seguir, o projeto gráfico da revista tenha análises futuras, principalmente ao que se refere ao grid e as aplicações tipográficas.

\section{Subcategorias:}

- Movimento da fonte: "[...] não existe o verdadeiro movimento, como nós o conhecemos; ele não se encontra no meio de comunicação, mas no olho do espectador, através do fenômeno fisiológico da 'persistência da visão" [...]" (DONDIS, 2007, p. 80).

- Tamanhos/corpos de fontes: Relação entre altura dos tipos e seu contexto "O tamanho de um tipo é uma questão de contexto. Proporções menores afetam a legibilidade [...]" (LUPTON, 2013, p. 37).

- Fontes com e sem serifa: "Traço adicionado ao início ou ao fim dos traços principais de uma letra" (BRINGHURST, 2001, p. 378).

- Caixa alta e baixa: uso de maiúsculas e minúsculas.

- Itálico: letra mais cursiva que o romano, "inicialmente desenvolvida na Itália do século 15 [...]" (BRINGHURST, 2001. p. 374).

- Bold: "Versão mais pesada de um determinado tipo. Pode variar de Semi Bold, Bold, Extra Bold, Black, Extra Black" (SPIKERMANN, 2011, p. 116).

- Alinhamento: "Os quatro modos de alinhamento formam a gramática básica da composição tipográfica [direita, esquerda, centralizado e justificado]" (LUPTON, 2013, p. 108).

\footnotetext{
"Algumas das propriedades da "persistência da visão" podem constituir a razão incorreta do uso da palavra 'movimento' para descrever tensões e ritmos compositivos nos dados visuais quando, na verdade, o que está sendo visto é fixo e móvel. [...] O processo da visão não é pródigo em repouso" (DONDIS, 2007, p. 81).
} 
- Cor: "Enquanto o tom está associado a questões de sobrevivência, sendo, portanto, essencial para o organismo humano, a cor tem maiores afinidades com as emoções" (DONDIS, 2007, p. 64).

- Figura e fundo: "Uma relação estável de figura e fundo existe quando uma forma ou figura destaca-se claramente de seu fundo [...]" (LUPTON, 2015, p. 106).

- Textura: "A textura é o elemento visual que com frequência serve de substituto para as qualidades de outro sentido, o tato" (DONDIS, 2007, p. 70).

\section{Usabilidade}

É a capacidade funcional em termos humanos de algo ser fácil de ser usado e não demandar esforço por um grupo específico de usuários, sem obter treinamento ou suporte, para atingir uma quantidade específica de tarefas em uma quantidade específica de cenários e ambientes, conforme já mencionado em tópico anterior.

\section{Subcategorias:}

- Visibilidade: "Quanto mais visíveis forem as funções, mais os usuários saberão como proceder" (ROGERS, 2013, p. 26).

- Feedback: De acordo com Rogers (2013):

O feedback se refere ao retorno de informações a respeito de que ação foi feita e do que foi realizado, permitindo à pessoa continuar a atividade. Vários tipos de feedback estão disponíveis para o design de interação - áudio, tátil, verbal, visual ou combinação destes. (ROGERS, 2013, p. 27).

- Restrições: "Refere-se a determinar formas de delimitar os tipos de interação de usuário que podem ocorrer em um determinado momento." (ROGERS, 2013, p. 27).

- Consistência: Segundo Rogers (2013): 
Refere-se a projetar interfaces de modo que tenham operações semeIhantes e utilizem elementos semelhantes para a realização de tarefas similares. [...] Um dos benefícios de interfaces consistentes, portanto, é serem mais fáceis de aprender e de usar (ROGERS, 2013, p. 28).

- Affordance: "Esse é um termo usado para se referir a um atributo de um objeto que permite que as pessoas saibam como utilizá-lo" (ROGERS, 2013, p. 28).

- Acessibilidade: Para Fadel e Licheski 2013:

Não diz respeito apenas ao público $\mathrm{PNE}^{2}$, mas também está relacionada à promoção de acesso a tecnologias de informação para pessoas de diferentes níveis de percepção, cognição, motricidade, além de diferenças de idade, gênero, classe social, cultura, escolaridade e de experiência no uso de tecnologias de informação e comunicação (FADEL; LICHESKI, 2013, p. 120).

A seguir, na figura 3, apresentamos as dez capas selecionadas para este estudo.

Figura 3 - Capas da Elle Brasil entre 2016 e 2017
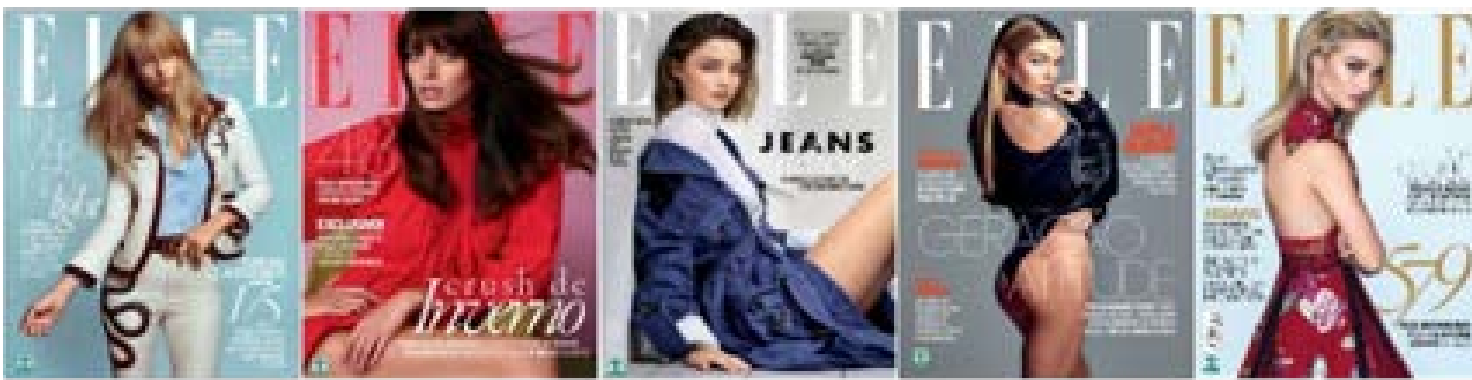

Capa 1

Capa 2

Capa 3

Capa 4

Capa 5

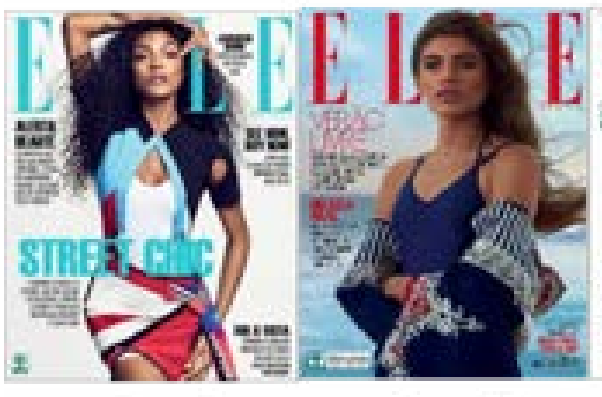

Capa 6

Capa 7

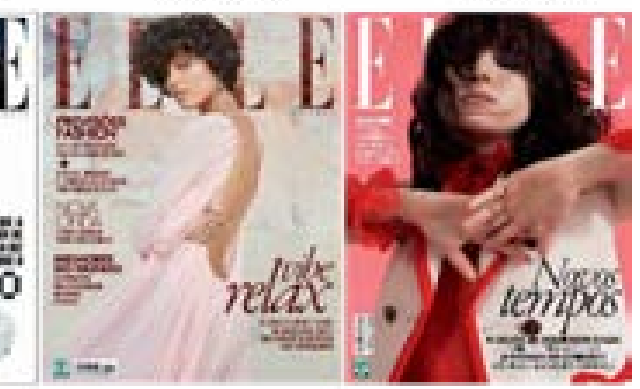

Capa 9

Capa 10

Fonte: Montagem elaborada pelas autoras com imagens capturadas via ferramenta GoRead.

2 PNE: Portador de Necessidades Especiais. 


\section{A performance da tipografia digital em Elle}

Conforme as categorias e subcategorias elencadas, apresentamos a análise do conjunto das capas, que ressalta padrões e destaca aspectos observados no corpus da pesquisa. A seguir temos as características de cada dispositivo utilizado (Quadro 1) e, em seguida, a captura de um dos momentos do processo de análise das capas de Elle, onde simultaneamente observamos a presença tipográfica em cada equipamento (Figura 5).

Quadro 1 - Equipamentos utilizados para o registro de capas da Elle Brasil em dispositivos para acesso à internet, meio digital

\begin{tabular}{|c|c|c|c|c|c|}
\hline EQUIPAMENTO & TELA/LENTE & PROCESSADOR & $\begin{array}{l}\text { MEMÓRIA } \\
\text { RAM }\end{array}$ & MARCA & MODELO \\
\hline $\begin{array}{l}\text { Câmera } \\
\text { Fotográfica* }\end{array}$ & $\begin{array}{l}\text { Lente Nikkor } 42 \mathrm{x} \\
\text { Wide Optical Zoom } \\
\text { ED VR } 4.3-180 \mathrm{~mm} \\
1: 3-5.9\end{array}$ & ---- & ------------ & Nikon & $\begin{array}{l}\text { Coolpix } \\
\text { P510 }\end{array}$ \\
\hline Desktop & $\begin{array}{l}24 \text { polegadas com } \\
\text { resolução de } 1900 x \\
1200 \text { pixels }\end{array}$ & $\begin{array}{l}\text { Intel Core i5 com } \\
2,3 \mathrm{GHz}\end{array}$ & $8 \mathrm{~GB}$ & Apple & $\begin{array}{l}\text { MacMini } \\
\text { OsX }\end{array}$ \\
\hline Notebook & $\begin{array}{l}14 \text { polegadas com } \\
\text { resolução de } 1366 x \\
768 \text { pixels }\end{array}$ & $\begin{array}{l}\text { Intel Core i5 com } \\
1,8 \mathrm{GHz}\end{array}$ & $6 \mathrm{~GB}$ & Dell & $\begin{array}{l}\text { Inspiron } \\
3241\end{array}$ \\
\hline Tablet & $\begin{array}{l}9,7 \text { polegadas com } \\
768 \times 1024 \text { pixels }\end{array}$ & $\begin{array}{l}\text { Dual Core A5 com } \\
16 \mathrm{~GB}\end{array}$ & $512 \mathrm{MB}$ & Apple & iPad 2 \\
\hline Smartphone & $\begin{array}{l}4 \text { polegadas com } \\
640 \times 1136 \text { pixels }\end{array}$ & $\begin{array}{l}\text { Apple AC com } 16 \\
\text { GB }\end{array}$ & $1 \mathrm{~GB}$ & Apple & iPhone $5 \mathrm{C}$ \\
\hline
\end{tabular}

Fonte: Elaborado pelas autoras. 
Figura 4 - Presença online em todos os dispositivos, ao mesmo tempo Elle Brasil (Capa 1)

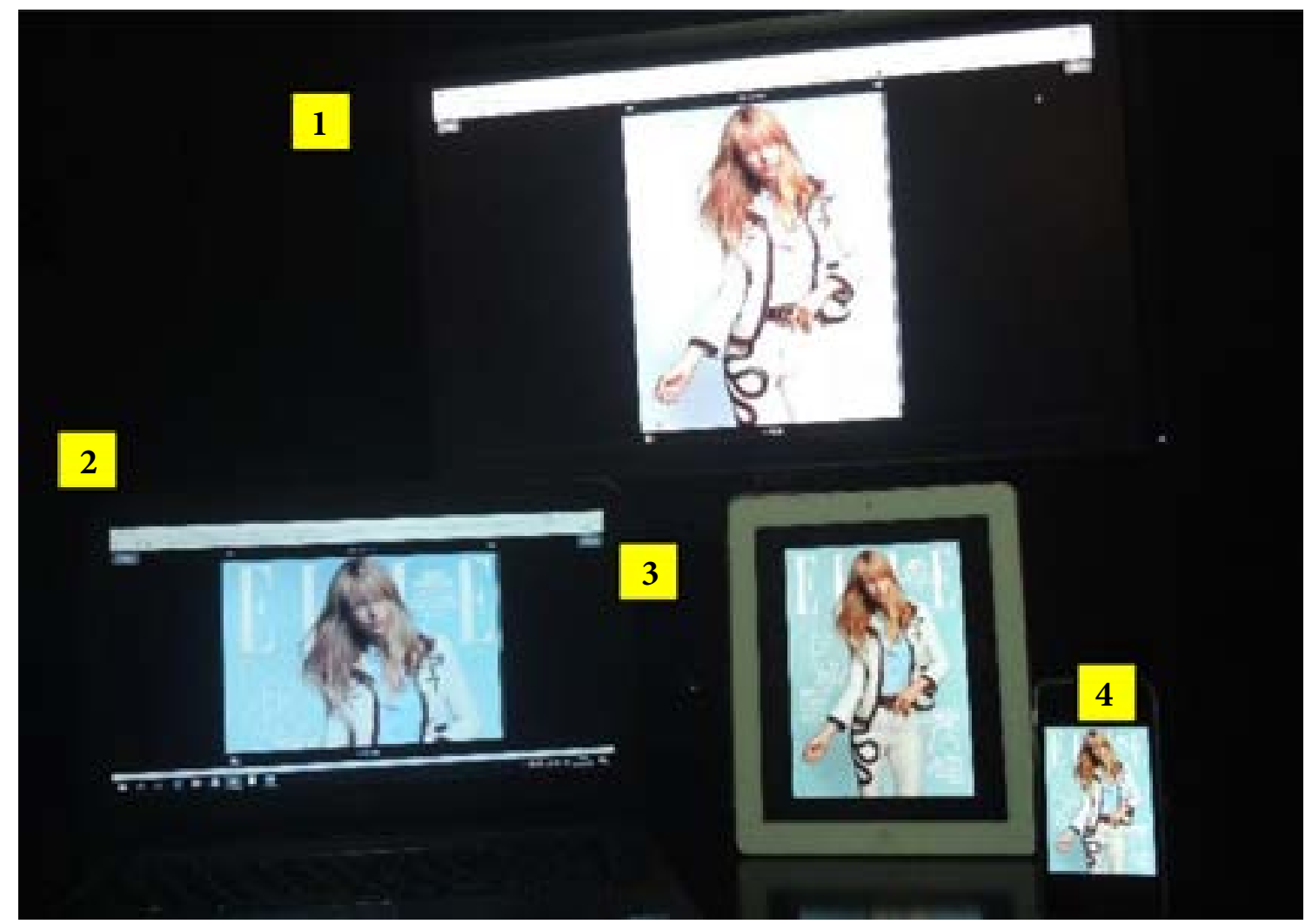

Legenda - 1: Desktop; 2: Notebook; 3: Tablet; 4: Smartphone.

Fonte: Elaborado pelas autoras.

Pudemos, assim, observar que quanto à Legibilidade, as capas possuem a tipografia como grande aliada no quesito "chamadas de capa", pois, diante da forma como é aplicada, mantém o equilíbrio entre as informações e o impacto visual. Acaba por trazer uma hierarquia e organização das informações, pelo tamanho das letras e pela disposição como são ali colocadas.

O alinhamento das capas estudadas costuma ser à esquerda para as chamadas que se localizam do lado esquerdo da capa, como também o texto será alinhado à direita quando próximo ao lado direito. Temos o título na maioria das vezes solto pela capa, sem lugar fixo.

A tipografia utilizada nas capas tem uso, na maioria das vezes, de fontes com e sem serifa e assim também ocorre frequentemente com o uso de caixa alta e baixa no texto ali publicado. No caso do uso dos tipos que não possuem serifa não há nenhum tipo de desconforto para a leitura, mesmo quando estão sobre imagens, conforme o contraste figura-fundo. 
A maior parte das fontes da capa da Elle Brasil utiliza o modo normal, porém o uso do bold ocorre para que haja ênfase em chamadas de capa. Estas são breves e o alinhamento as auxilia porque, já que são textos sintéticos, a disposição pode trazer um impacto que motive o público à leitura, o que é bastante aprazível.

As fotografias de capa em sua maioria são sempre de tamanho que abranja a totalidade do espaço. Costumam ser coloridas e desempenham papéis importantes como auxiliar a capa a propagar o veículo, como também corroborar para a sua identidade visual.

As capas de Elle marcam estilo e a perenidade da marca, que se expressam pelas poucas mudanças ocorridas em seu logotipo e nas famílias tipográficas que as compõem. É uma revista voltada à moda e ao estilo, que busca atrair novidade e sofisticação do conteúdo e da forma. O contraste que existe entre as fotografias e a tipografia valoriza o projeto gráfico da revista, uma marca de sua identidade visual em meio às outras.

Há vezes que a tipografia ganha textura, porém isso é feito de maneira distinta somente para algumas edições, pois nota-se que a prioridade é valorizar a mensagem que o título e as breves chamadas de capa trazem, sendo que não podemos negar o fato de que as imagens sempre tentam protagonizar a capa, já que é uma revista de moda. Queremos dizer que a textura se torna presente para reforçar a mensagem que a capa traz, por exemplo, o uso da textura Matrix no logotipo da Elle Brasil, conforme apresentamos a seguir, na figura 6. 
Figura 5 - Capa da revista Elle Brasil - Logotipo com textura Matrix

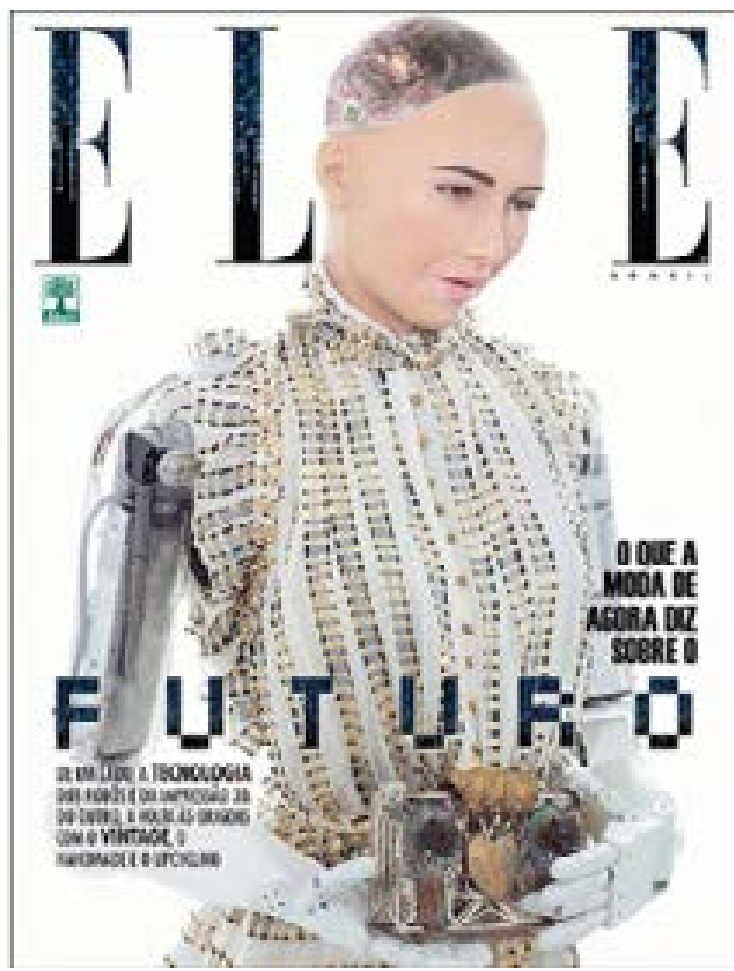

Fonte: Elle Brasil, $2016 \mathrm{a}$.

Figura 6 - Cartaz do filme The Matrix (1999)

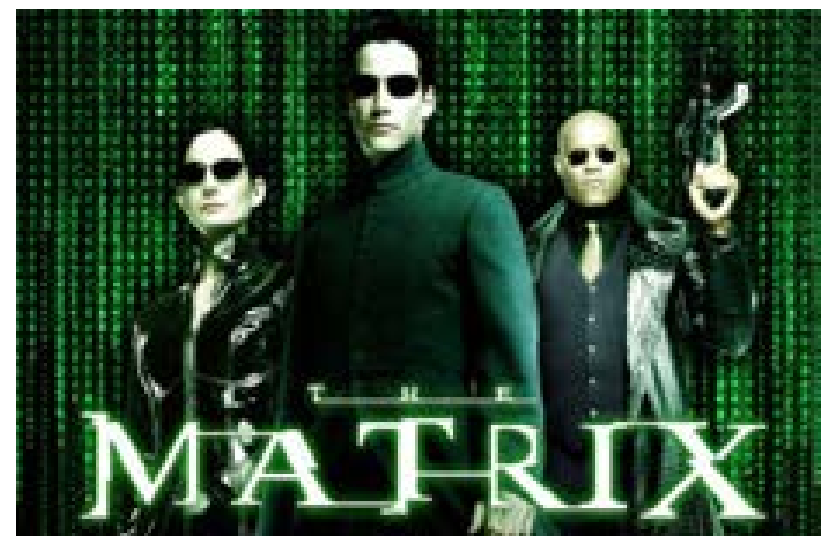

Fonte: MARTINS, C., 2012. 
Figura 7 - Textura Matrix (1999)

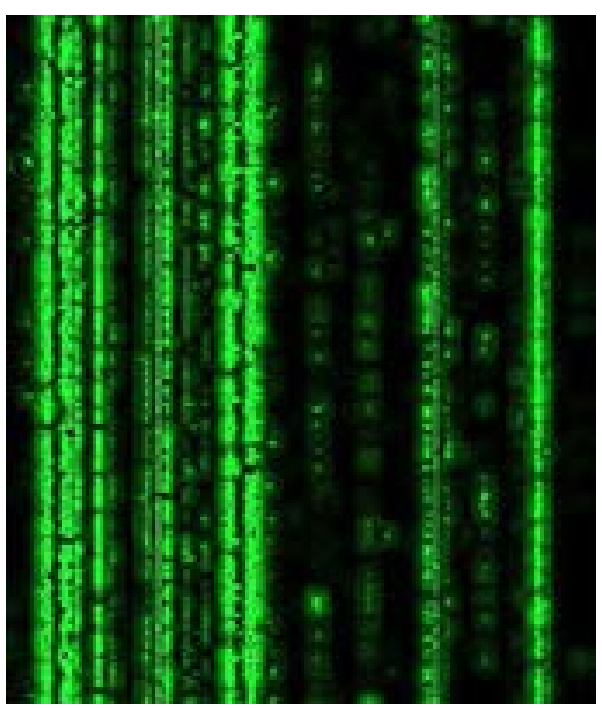

Fonte: ANDRADE, D. S., 2010.

Outro tópico que vale a pena analisar, apesar de não estar entre as categorias analisadas, é o fato de que o grid ${ }^{3}$ da capa da revista Elle Brasil sempre é respeitado e apesar de parecer que limita a ideia criativa do designer, fornece oportunidade criativa pelos usos diversos das famílias das fontes que ali estão.

O uso das cores, o alinhamento, o uso de bold ou não, caixas altas ou baixas levam a uma uniformidade para que haja localização das informações. Sabemos que são vários detalhes para que tenhamos a tipografia aplicada corretamente. Vamos lembrar que Ali (2009) disse que a revista dispõe de 5 segundos para atrair atenção do leitor e que nesse intervalo deve transmitir a identidade e o conteúdo da publicação, assim, devemos considerar que o investimento em tempo para o desenvolvimento da capa de revista é de grande importância.

Como pode ser observado, as capas da versão impressa são as mesmas da versão digital, sendo que a legibilidade depende não só do planejamento da equipe de profissionais da revista, que se apropria dos diversos elementos da tipografia para, ao lançar mão deles, dar movimento, contraste, dinamismo e destaques, como também exige criatividade na escolha dos destaques, e como apresentá-los, e sintonia com a equipe editorial, preservando a sintonia entre fotografia, tipografia e conteúdo editorial. Para que esse equilíbrio se dê também

3 Grid: é a organização visual dos elementos dentro de um espaço utilizando linhas horizontais e verticais que se cruzam entre si. (Disponível em: http://designculture.com.br/usando-o-grid-para-melhorar-a-percepcao-visual-2/. Acesso em 18 fev. 2017.) 
na versão digital, uma vez que o meio é outro, é preciso pensar nos impactos das escolhas para a legibilidade e nas condições de recepção do leitor.

Quanto à usabilidade, um primeiro aspecto a considerar é quanto ao tamanho da tela do dispositivo em uso, que deve proporcionar conforto visual e manter em alta a legibilidade. Pode-se constatar que, em todas as capas analisadas, apenas nas capas de números quatro e sete houve prejuízo, sendo que o elemento cor causou o conflito quando aplicado sobre a tipografia em contraste com o fundo, prejudicando a legibilidade do texto.

Figura 8 - Capas da Elle Brasil que apresentaram prejuízo da comunicação visual, edições de agosto de 2016, n 339 e de novembro de 2016, n 342
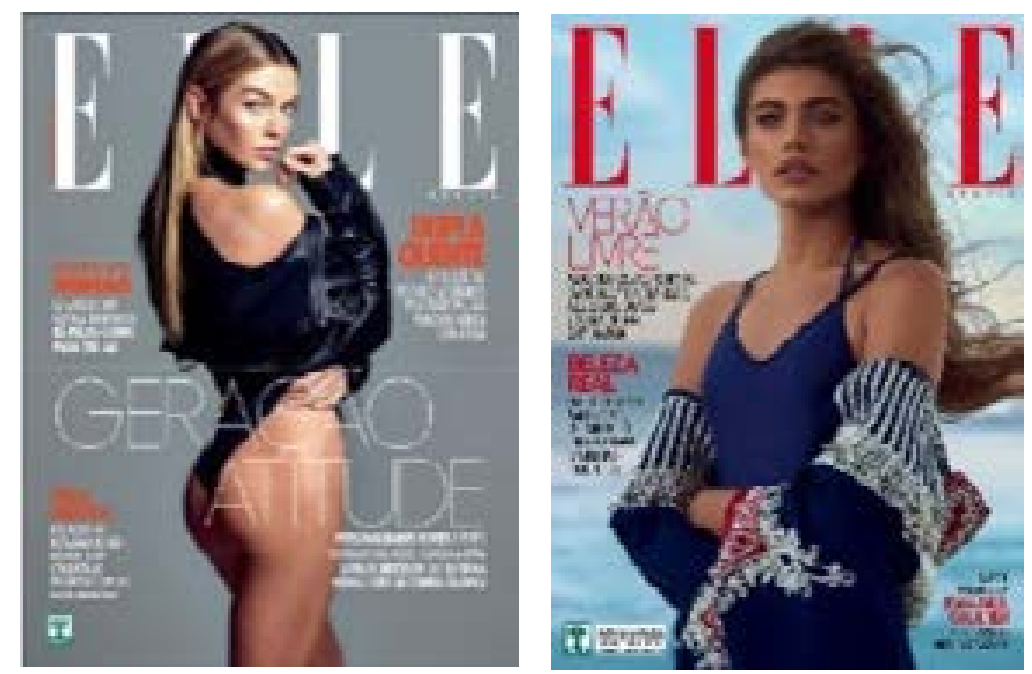

Fontes: Elle Brasil, 2016b; à direita, Elle Brasil, 2016c.

Outro ponto a considerar é que o smartphone é o dispositivo que requer maior interatividade com a tipografia da capa, em razão do menor tamanho da tela. $\mathrm{A}$ usabilidade é mais evidente quando se faz necessária a leitura nessa plataforma e o touch é fundamental para a ampliação do tamanho das letras, imagens etc., com o objetivo de que o leitor tenha condições de enxergar e entender o conteúdo. Conforme apresenta Lupton (2015), os diversos tipos de gestos e toques ajudam a compensar algumas perdas, especialmente quando se trata de telas menores. É preciso buscar alternativas de interatividade para que haja condições de o público alcançar o conteúdo satisfatoriamente.

Observando as capas de Elle no smartphone, foi necessário ampliar a imagem para ler todas as chamadas de capa - sendo que ao ampliar houve condições de verificação todos os detalhes das fontes. As imagens ampliadas não apresen- 
tam distorção, ou seja, há planejamento para que sejam utilizadas em todos os dispositivos e que sejam preservadas as suas características. Torna-se, então, necessário afirmar que a produção do conteúdo deve estar de acordo com o uso amplo em todos os dispositivos e que este conteúdo esteja preparado para ser expandido, reduzido, levado de um lado a outro na tela etc., para que a leitura e a legibilidade sejam de padrão satisfatório àquele receptor das mensagens.

O smartphone já é considerado o dispositivo por meio do qual mais se acessa conteúdos digitais. Portanto, a boa experiência do público com o veículo deve ser plena e a probabilidade de leitura por meio de um smartphone, então, deve ter grande relevância quando na preparação das capas digitais -, e no restante do conteúdo da revista digital também.

Outra observação quanto à usabilidade é que no notebook a capa não possui adequação para aparecer inteira: é preciso rolar a imagem para conhecer a capa como um todo. Observação essa que vale somente para esse dispositivo, já que nos demais não ocorre.

No que diz respeito exclusivamente sobre a tipografia, permanece a afirmação de que ela funciona plenamente no notebook não somente pelo tamanho de sua tela - que apenas perde para o tamanho da tela do desktop-, mas também pelo dispositivo oferecer a qualidade adequada para todas as utilizações das fontes em sua capa. Essa qualidade também está presente nos tablets.

Temos aí a constatação de que a rolagem é um dos artifícios que podem ser utilizados para atingir satisfatoriamente o receptor sendo que o nível de sucesso quando analisados pelo foco das subcategorias visibilidade, consistência e affordance é muito positivo.

Sobre a imagem da capa em si, vimos mais uma vez que quando há essa necessidade, a Elle não perde as suas características (não distorce, não granula etc.). 0 uso do design responsivo ${ }^{4}$ valoriza a flexibilidade como condição necessária para que a mensagem seja adaptada ao dispositivo que a apresente, acomodando-se de forma tal que mantenha o estímulo e a motivação para que o receptor continue absorvendo o conteúdo exposto. Repetimos abaixo o que Lupton (2015) afirma:

Os adeptos do design responsivo planejam e desenvolvem páginas da web que exibem seu conteúdo de maneira diferente dependendo de como o usuário estiver visualizando o site ao invés de criar versões diferentes e autônomas para diferentes dispositivos (LUPTON, 2015, p. 56).

4 Design responsivo: "O design responsivo $\{. .$.$\} consegue responder ao tamanho da tela para se adequar$ da melhor forma” (ALTERMANN, 2012). 
Ao confrontar legibilidade e usabilidade percebemos nas diversas plataformas digitais que as demandas para uma boa comunicação visual, para a identidade do veículo, particularmente para uma revista que depende de estilo e sofisticação e para um público mais jovem e feminino, são contempladas.

\section{Considerações finais}

Analisar a tipografia digital é essencial para observar as características do meio e as condições de recepção. É dessa forma que a comunicação visual por meio da tipografia no meio digital se realiza. A legibilidade depende das condições de usabilidade do meio, portanto, a performance eficaz da tipografia digital não se efetiva sem se considerar as condições de usabilidade, as quais implicam diretamente nas características técnicas de cada plataforma digital, como tamanho e resolução das telas.

Nesse sentido, é possível destacar que nem sempre se leva em consideração essas condições, pois é necessário avaliar o processo de comunicação, na sua complexidade, no âmbito da produção e da recepção, da forma e do conteúdo e do acesso tecnológico, para poder garantir a legibilidade.

No caso da Elle Brasil, constatamos que o tamanho das telas é de grande valia para a legibilidade, assim como o fato de que a tipografia digital carece fundamentalmente de estar ajustada para as mais diferentes formas de visualização (diferentes dispositivos de acesso à web como desktops, notebooks, tablets e smartphones), sempre que houver a migração da versão impressa para a versão digital e sua oferta simultânea. Por isso, ter performance eficaz na comunicação visual é um exercício simultâneo de aplicação da tipografia em plataformas que se relacionam, o digital e o impresso, que se tornam hoje expressões de identidade visual das revistas (e de outros veículos jornalísticos), como a Elle Brasil.

Além disso, verificamos que no ambiente digital a usabilidade foi o grande fator que trabalhou em prol da tipografia nas observações e análises que fizemos, pois apesar de algumas capas do corpus analisado não apresentarem tipografia de maneira satisfatória, nas subcategorias de análise da usabilidade vimos que é possível haver certo ajuste que venha a deixá-la ideal, como, por exemplo, o uso do touch, para redimensionar o tamanho das fontes e/ou arrastar telas e imagens.

Quanto à acessibilidade, essa depende principalmente dos recursos dos dispositivos, no caso da Elle, eles estavam prontos a atender às necessidades dos receptores, inclusive os portadores de algum tipo de deficiência visual. Porém, observamos também que a cor é algo que a usabilidade não tem como resolver. Em algumas capas 
da Elle Brasil, determinadas cores em contraste com a cor do fundo prejudicaram a legibilidade, conforme vimos na figura 6. Por isso, é fundamental ter cautela para aplicação de cores, especialmente em se tratando de tipografia. Há necessidade de testes em todos os suportes, para uma melhor legibilidade/leiturabilidade.

Também observamos que a boa performance da tipografia é usada para representar a identidade da revista Elle como se fosse a sua própria letra, seu estilo de escrita. No ambiente digital, ela assume o papel da representação visual da linguagem escrita da revista. E mais: estando presente em dispositivos digitais, promove a legitimidade das edições impressas da revista quando on-line, pela ampla possibilidade de acesso à publicação por meio dos dispositivos digitais e móveis. A revista adequa-se ao outro ambiente e amplia a sua presença na mídia, agregando recursos multimídia (áudio, vídeo, touchscreen, telas de retina etc.), além de a interatividade com o público se ampliar. Em todas as versões para todos os dispositivos utilizados, a tipografia de cada edição da revista apresentou-se majoritariamente preparada para atender às necessidades de leitura em dispositivos digitais, seja para o simples toque ou clique, para ampliação, para deslocamento horizontal, vertical, diagonal das telas etc.

Assim, em futuros estudos há a necessidade de se considerar que a capacidade de leitura nos meios de comunicação poderá ser influenciada pela busca incessante do diálogo entre tipografia, fotografia e conteúdo editorial em produtos jornalísticos, aliadas às potencialidades do meio e às condições de recepção e de interação - 0 que representa o processo de comunicação. Pensamos que mais do que mensagens, como nos ensina McLuhan, meios e mensagens são dois lados da mesma moeda.

\section{Referências}

MARTINS, C. Análise da trilogia Matrix. 2012 - A Era de Ouro, [200-?]. Disponível em: http://2012aeradeouro.webnode.com.br/products/analise-do-filme-matrix/. Acesso em: 6 mar. 2017.

ALI, F. A arte de editar revistas. São Paulo: Companhia Editora Nacional. 2009.

ALTERMANN, D. Design Responsivo: entenda o que é a técnica e como ela funciona. Midiatismo, 2012. Disponível em: https://www.midiatismo.com.br/design-responsivo-entenda-o-que-e-a-tecnica-e-como-ela-funciona. Acesso em: 26 mar. 2018.

ANDRADE, D. S. Efeito Matrix. In: Blog do Dario, 21 out. 2010. Disponível em: http:// photoshopindesign.blogspot.com/2010/10/efeito-matrix.html. Acesso em: 27 fev. 2019. 
BARBOSA, S. Entrevista I [fev.2017]. Entrevistador: Audrey Marques Duarte. Salvador, 14 fev. 2017. 1 arquivo .mp3 (52 min.).

BARBOSA, S. Jornalismo convergente e continuum multimídia na quinta geração do jornalismo nas redes digitais. In: CANAVILHAS, J. (org.). Notícias e Mobilidade: O Jornalismo na Era dos Dispositivos Móveis. Covilhã, Portugal: LABCOM-UBI. Disponível em: http://citeseerx.ist.psu.edu/viewdoc/download?doi=10.1.1.878.4768\&rep=rep1\&type=pdf\#page=41. Acesso em: 20 mar. 2018.

BRINGHURST, R. Elementos do estilo tipográfico. 3.ed. São Paulo: Cosac Naify, 2011.

CALDWELL, Cath; ZAPATERRA, Yolanda. Design editorial: Jornais e revistas / mídia impressa e digital. São Paulo: Gustavo Gilli, 2014.

CANEVACCI, M. Antropologia da comunicação visual. Rio de Janeiro: DP\&A, 2001.

CARRAMILLO, M. C. Produção gráfica II: papel, tinta, impressão e acabamento. São Paulo: Global, 1997.

ELLE - PARA MADAMES E MADEMOISELLES. Correio do Povo. Porto Alegre, 2 jul. 2014. Disponível em: http://www.correiodopovo.com.br/blogs/correiofeminino/2014/07/14028/elle-para-madames-e-mademoiselles/. Acesso em: 22 fev. 2017.

COSTA, S. R. Minidicionário do discurso eletrônico-digital. Belo Horizonte: Autêntica, 2009.

DONDIS, D. A. A sintaxe da linguagem visual. 3. ed. São Paulo: Martins Fontes, 2007.

DUARTE, A. M. A revista, o design gráfico e a tipografia digital: um estudo de caso sobre as capas de Elle. 2017. 348p. Tese (Doutorado em Comunicação Social) - Escola de Comunicação, Educação e Humanidades, Universidade Metodista de São Paulo, São Bernardo do Campo, 2017.

FADEL, L.; LICHESKI, L. (In)acessibilidade digital. InfoDesign: revista brasileira de design da informação, São Paulo, v.10, n. 2. p.104-122, 2013.

FARIAS, P. Tipografia digital: o impacto das novas tecnologias. 4. ed. Teresópolis: 2AB, 2013.

GABRIEL, Martha. Marketing na era digital: conceitos, plataformas e estratégias. São Paulo: Novatec, 2010.

ABRIL COMUNICAÇÕES S/A. GoRead. Grupo Abril, 2016. Ferramenta digital para produtos editoriais. Disponível em: https://www.goread.com.br/aplicativos. Acesso em: 14 jan. 2019.

ELLE BRASIL. São Paulo, 2016, n. 343, dez. 2016a. Disponível em: http://webviewer.iba. com.br/viewer?ticket=cfcdco61c4722b77824c978c88d6f999. Acesso em: jan. 2017. 
ELLE BRASIL. São Paulo, 2016, n. 339, ago. 2016b.Disponível em: http://webviewer. iba.com.br/viewer?ticket=17faoga6df3e53bcab277c62aaa8dfg8. Acesso em: jan. 2017.

ELLE BRASIL. São Paulo, 2016, n. 339, nov. 2016c. Disponível em: http://webviewer.iba. com.br/viewer?ticket=cfcdco61c4722b77824c978c88d6f999. Acesso em: jan. 2017.

GRUZYNSKI, A., Design editorial e publicação multiplataforma. InTexto, Porto Alegre, n. 34, p. 571-588, set./dez. 2015. https://doi.org/10.19132/1807-8583201534.571-588

GUIMARÃES, L. Conceitos, fundamentos e as três dimensões do jornalismo visual. Revista Comunicação Midiática, v.8, n.3, p. 236-253, set./dez. 2013.

LONGHI, R. R. Infografia on-line: narrativa intermídia. Estudos em Jornalismo e Mídia, v. 6, n. 1, p. 187-196, jan. /jul. 2009. Disponível em: https://periodicos.ufsc.br/index.php/ jornalismo/article/view/1984-6924.2009v6n1p187. Acesso em: 27 maio 2017. https:// doi.org/10.5007/1984-6924.2009v6n1p187

LUPTON, E. (org.). Tipos na tela. São Paulo: Gustavo Gili, 2015.

LUPTON, E. Pensar com tipos: guia para designers, escritores, editores e estudantes. 2. ed. São Paulo: Cosac Naify, 2013.

MARQUES, T. Tipografia: estrutura e conceitos digitais. Convergências. In: Revista de Investigação e Ensino das Artes. 2. ed. Castelo Branco: IPCB (Instituto Politécnico Castelo Branco), 2008. ISSN: 1646-9054. Disponível em: http://convergencias.esart. ipcb.pt/article/30. Acesso em: 8 fev. 2017.

MARTINS, C. Análise da trilogia Matrix. Disponível em: http://2012aeradeouro.webnode. com.br/products/analise-do-filme-matrix/. Acesso em: 6 mar. 2017.

MUNARI, B. Diseño y comunicación visual: contribución a una metodología didáctica. Barcelona: G. Gili, 1997.

NIELSEN, J. Usability enginnering. Boston: Academic Press, 1993. https://doi.org/10.1016/ B978-0-08-052029-2.50009-7

Secretaria de Comunicação Social da Presidência da República. Pesquisa Brasileira de Mídia 2016. Brasília, 2016. Disponível em http://www.secom.gov.br/atuacao/pesquisa/ lista-de-pesquisas-quantitativas-e-qualitativas-de-contratos-atuais/pesquisa-brasileira-de-midia-pbm-2016.pdf/view. Acesso em: 10 de jan. 2018.

RADFAHRER, L. Design web design. São Paulo: Market Press, 2000.

ROGERS, Y. Design de interação: além da interação humano-computador. 3. ed. Porto Alegre: Bookman, 2013. 
SCHACKEL, B. Usability: context, framework, definition, design and evaluation. In: SCHACKE, B.; RICHARDSON, S. J. (eds.). Human factors for informatic usability. New York: Cambridge University Press, 1991. p. 21-37.

SPIEKERMANN, E. A linguagem invisível da tipografia: escolher, combinar e expressar com tipos. São Paulo: Blücher, 2011.

\section{Dados das autoras}

Audrey Marques Duarte: professora@audreyduarte.com.br

Professora do Instituto de Ciências Sociais e Comunicação da Universidade Paulista

- UNIP (Campus Santos). Doutora em Comunicação Social pela Universidade Metodista de São Paulo - UMESP.

Endereço da autora: Universidade Metodista de São Paulo, Programa de PósGraduação em Comunicação Social. Campus Rudge Ramos. Rua Alfeu Tavares, 149, Rudge Ramos, 09.641-00o - São Bernardo do Campo (SP) - Brasil

\section{Marli dos Santos: marlijor58@globo.com}

Professora do Programa de Pós-Graduação em Comunicação da Faculdade Cásper Líbero -FCL. Doutora em Ciências da Comunicação pela Universidade de São Paulo -USP.

Endereço da autora: Faculdade Cásper Líbero, Programa de Pós-Graduação em Comunicação. Avenida Paulista, 900 - Edifício Fundação Cásper Líbero, Bela Vista, 01.310-940 - São Paulo (SP) - Brasil 